\title{
Multiple Voltage Disturbance Compensation in Distribution Systems using DVR
}

\author{
Syed Suraya \\ Department of EEE \\ GATES Institute of Technology \\ Anantapuram, India \\ syedsuraya@gmail.com
}

\author{
Saad F. Al-Gahtani \\ Department of Electrical Engineering \\ King Khalid University \\ Abha, Saudi Arabia \\ saljbar@kku.edu.sa
}

\author{
Shaik Mohammad Irshad \\ Department of Electrical Engineering \\ King Khalid University \\ Abha, Saudi Arabia \\ sirshad@kku.edu.sa \\ Majahar Hussain Mahammad \\ Department of Electrical Engineering \\ King Khalid University \\ Abha, Saudi Arabia \\ mhmohamad@kku.edu.sa
}

\author{
Mohammad Fazle Azeem \\ Department of Electrical Engineering \\ College of Engineering \\ King Khalid University \\ Abha, Saudi Arabia \\ and \\ Department of Electrical Engineering \\ Zakir Husain College of Engineering \\ Aligarh Muslim University \\ Aligarh, India \\ mazeem@kku.edu.sa
}

\begin{abstract}
The subject of power quality is gaining much interest nowadays. With the sophisticated sensitive electrical devices available in the market, power stations should ensure qualified and eminent power to the point of utilization. Bad voltage conditions in a power system can cause a malfunction at the point of utilization. Dynamic voltage restorer (DVR) is a reliable power electronic offsetting device which when engaged in the power system is effectual in the operation of compensating voltage sag/swell. In this research work, a DVR for offsetting multiple voltage disturbances in a power system is presented and a novel control strategy to trigger power switches in DVR is proposed. The proposed novel control methodology is compared with Synchronous Reference Frame (SRF) theory-controlled DVR. The simulation model is designed and the analysis with MATLAB/SIMULINK is presented.
\end{abstract}

Keywords-Voltage disturbance; sag; swell; DVR; novel control

\section{INTRODUCTION}

The power quality topic is of high importance to the power sector as the loads are extremely responsive to power quality disturbances. Huge economic losses can occur due to bad power quality. High grade sensitive non-linear power electronic equipment is employed at the load points causing deformation of system parameters or degradation of the system $\lceil 1-4\rceil$. The knowledge regarding the different forms in which power quality is deteriorated presents the solution methodology. This information is also important in identifying the origin of device failure. Power system quality is often reduced due to voltage noise. Voltage sags/swells are said to have major effects on power systems [1]. Voltage sags/swells can reduce the life time of a device or can even damage the equipment. Voltage sags can be classified as symmetrical and unsymmetrical depending on the nature of the signal [4-5]. Phase to ground faults might generate voltage sags in the power system. On the other hand, swells in voltage can be generated by abrupt switching of capacitor banks or reactive power generating devices. Voltage quality is ensured by using controllers in series which compensate voltage issues. The circuit diagram of a series controller in a power system is shown in Figure 1. FACTS (Flexible AC Transmission System) controllers are developed to mitigate the power quality issues in the power system. DVR (Dynamic Voltage Restorer) [6-8] is a series connected FACTS controller which addresses voltage issues in a power system [9101. This paper presents a DVR for the compensation of multiple voltage disturbances in the power system. A novel control strategy to trigger power switches in DVR is proposed and compared with SRF theory-controlled DVR.

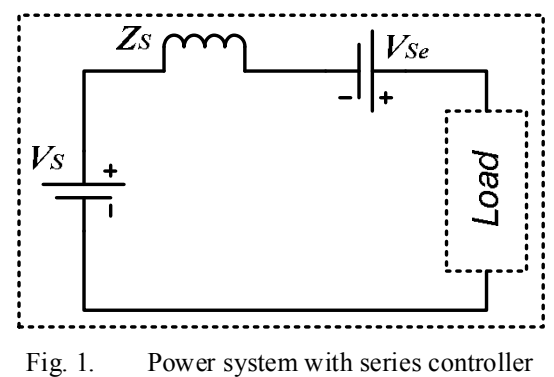

\section{DYNAMIC VOLTAGE RESTORER}

The Dynamic Voltage Restorer (DVR) is a power electronic component placed in series with the electrical transmission or distribution system. The series compensating DVR device guards the perceptive loads from voltage issues in the power system. The DVR operates on the principle of inducing selective frequency-based voltage magnitude essential to reinstate the load voltage when the source voltage is fed with sag/swell/disturbance nature. The DVR can also be stated as solid state power electronic switching device that induces synchronous voltage in series to power system line. The basic DVR configuration in a power system is shown in Figure 2. DVR comprises of an energy source and an IGBT based power Corresponding author: Shaik Mohammad Irshad 
converter. The power system is in series with the DVR set-up. A capacitor or a battery source can be used as an energy source for the DVR. A fault in the power system might generate voltage sag/swell in the propagating signal. The controller of the DVR identifies the sag/swell and the solid-state DVR generates proportionally compensating voltage signals, fed to the power system load, in such a way that the load devices are not subjected to sag/swell while the source component is still in fault mode [11].

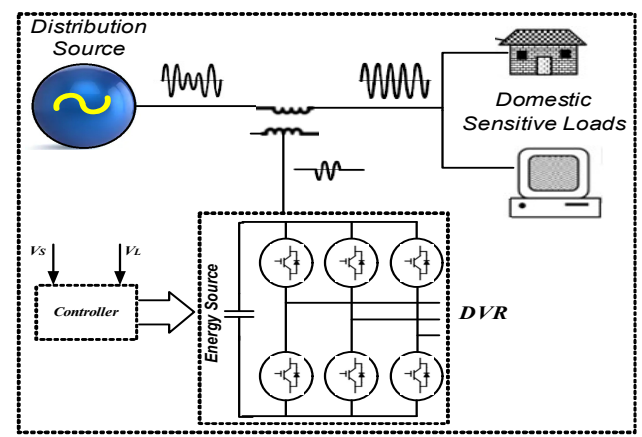

Fig. 2. DVR in a power system

\section{DVR CONTROL STRATEGY}

\section{A. Conventional SRF Thoery for Controling DVR}

SRF theory generates current reference signals by transforming current signals to rotating coordinates and then again back to the original format. Load currents are transformed from the stationary 'abc' frame to the rotating ' $\mathrm{dq}$ ' frame using (1) which generates currents in 'dq' coordinates [12]:

$$
\left[\begin{array}{l}
i_{d} \\
i_{q} \\
i_{0}
\end{array}\right]=\sqrt{2 / 3}\left[\begin{array}{ccc}
0 & -\frac{1}{2} & -\frac{1}{2} \\
0 & \frac{\sqrt{3}}{2} & -\frac{\sqrt{3}}{2} \\
\frac{1}{2} & \frac{1}{\sqrt{2}} & \frac{1}{\sqrt{2}}
\end{array}\right]\left[\begin{array}{l}
i_{a} \\
i_{b} \\
i_{c}
\end{array}\right]
$$

The loss component is calculated from the PI controller where the inputs are the actual voltage and the reference DC voltage level of the DVR energy source. The rotating 'dq' frame coordinates are again inverse-transformed to obtain the reference current signals in the 'abc' coordinate system as shown in (2):

$$
\left[\begin{array}{l}
i_{a} \\
i_{b} \\
i_{c}
\end{array}\right]=\sqrt{2 / 3}\left[\begin{array}{ccc}
\operatorname{Cos} \theta & -\operatorname{Sin} \theta & \sqrt{\frac{1}{2}} \\
\operatorname{Cos}(\theta-2 \pi / 3) & -\operatorname{Sin}(\theta-2 \pi / 3) & \sqrt{\frac{1}{2}} \\
\operatorname{Cos}(\theta+2 \pi / 3) & -\operatorname{Sin}(\theta+2 \pi / 3) & \sqrt{\frac{1}{2}}
\end{array}\right]\left[\begin{array}{l}
i_{d} \\
i_{q} \\
i_{0}
\end{array}\right]
$$

The generated reference current signals in the 'abc' coordinate system are compared with the three-phase actual current wave to setup control signals to the power switches of DVR. This theory involves multiple mathematical and arithmetic operations while generating reference current signals making the control system complex [13]. The overall power system consisting of the DVR controlled with SRF theory is shown in Figure 3.

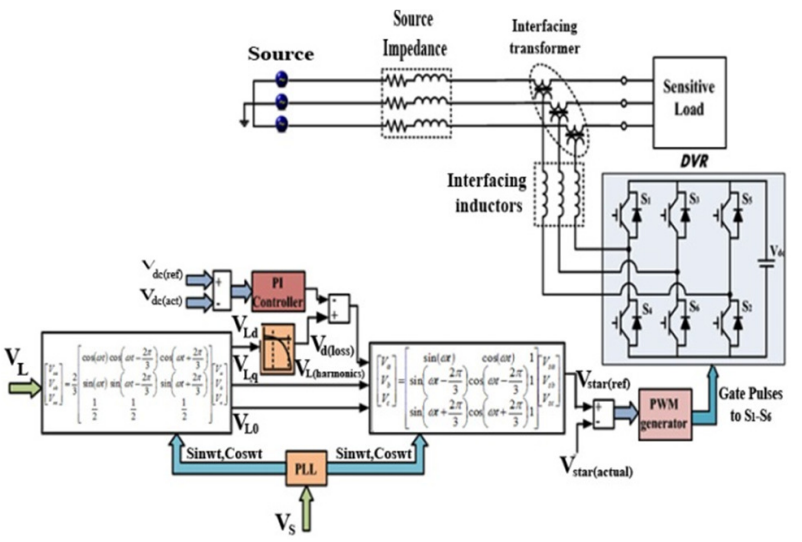

Fig. 3. Overall power system DVR controlled with SRF theory

\section{B. Proposed Novel Control Theory for DVR}

Figure 4 illustrates the overall power system with a DVR controlled with the proposed novel control methodology which generates control pulses to DVR. The novel control methodology senses the line voltage of the system and is split into three individual phases: $V_{a}, V_{b}$ and $V_{c}$. The three voltage error signals $V_{a e}, V_{b e}$ and $V_{c e}$ from each phase to the pulse width modulation generator are:

$$
\begin{gathered}
V_{a e}=\left(V_{\text {maxrefa }}-\sqrt{V_{\alpha}^{2}+V_{\beta}^{2}}\right) \sin \left(\omega t-0^{\circ}\right) \\
V_{b e}=\left(V_{\text {maxrefb }}-\sqrt{V_{\alpha}^{2}+V_{\beta}^{2}}\right) \sin \left(\omega t-120^{\circ}\right) \\
V_{c e}=\left(V_{\text {maxrefc }}-\sqrt{V_{\alpha}^{2}+V_{\beta}^{2}}\right) \sin \left(\omega t-240^{\circ}\right)
\end{gathered}
$$

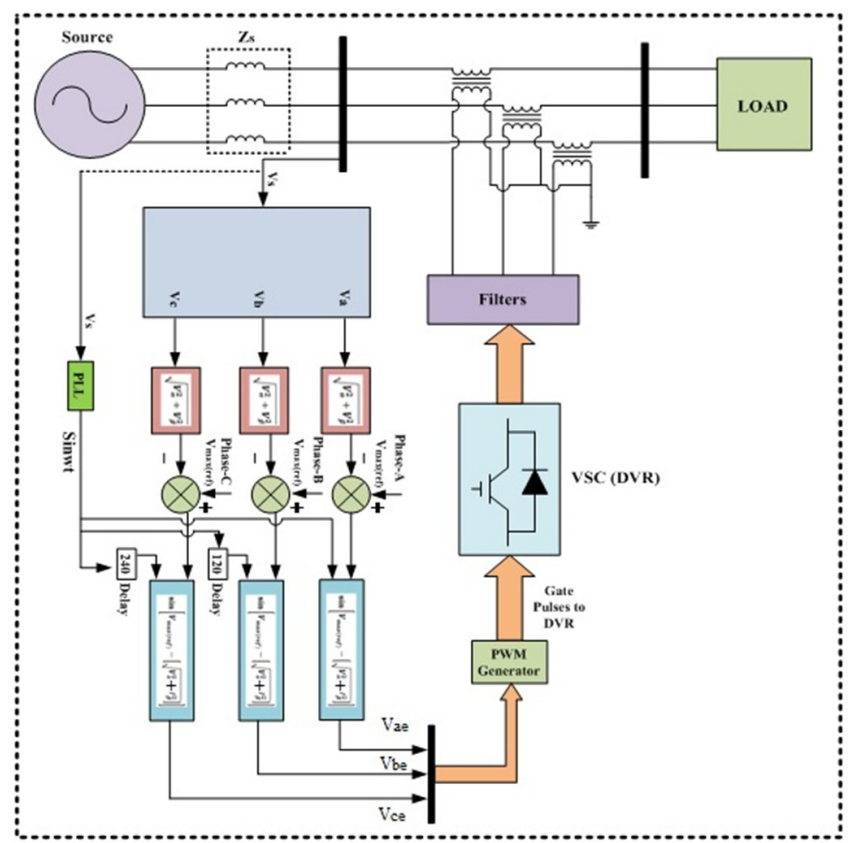

Fig. 4. Overall DVR control-power system with novel control theory

In this proposed control technique of governing DVR, the trigonometric function's information required is very less and 
also the transformations blocks that are utilized in SRF theory are not used. This prevents complex problematic calculations and makes the control technique facile [14-16]. The data of $V_{a}$, $V_{b}, V_{c}$ are obtained from the source voltage. The product of $V_{a}$ with $V_{a}$ gives $V_{\alpha}^{2}$. This signal is added to $V_{\beta}^{2}$ signal which is obtained by adding a $90^{\circ}$ delay to $V_{a}$. Square-root is applied to the obtained signal. The resultant signal is the maximum value. The maximum value is correlated with $1 \mathrm{pu}$ value. This resultant magnitude is multiplied with sinusoidal information obtained from the phase locked loop. The resultant signal is the reference signal for $V_{a}$. Similarly, this arithmetic procedure is followed for phase B and phase C with delay of $120^{\circ}$ and $240^{\circ}$ respectively. The three phase error signals are processed through the PWM generator to produce gate pulses to the power switches of DVR [17-19]. Figure 5 illustrates the control strategy of the novel control theory.

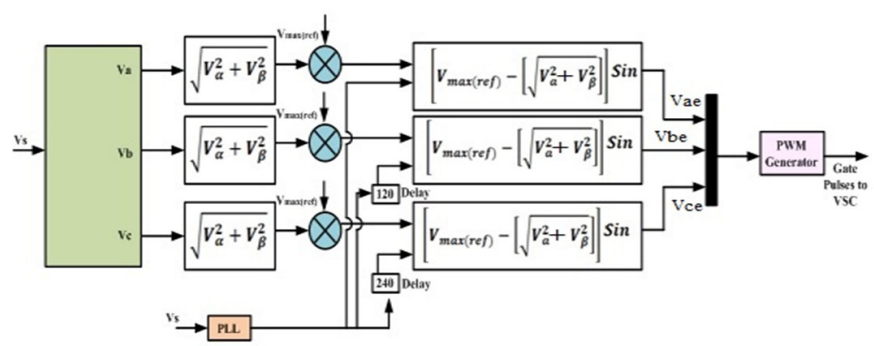

Fig. 5. Control strategy for DVR with the novel control theory.

\section{RESULT DISCUSSION AND ANALYSIS}

The system parameters considered with the SRF theory and the novel control method are represented in Table I.

TABLE I. SYSTEM CONFIGURATION

\begin{tabular}{|c|c|}
\hline Parameters & Value \\
\hline AC line voltage & $440 \mathrm{~V}$ \\
\hline Frequency & $50 \mathrm{~Hz}$ \\
\hline Load power & $10 \mathrm{~kW}$ \\
\hline DC voltage source & $550 \mathrm{~V}$ \\
\hline
\end{tabular}

The overall power system with DVR is shown in Figure 6. The Simulink model for control strategy for DVR with the novel control theory is shown in Figure 7.

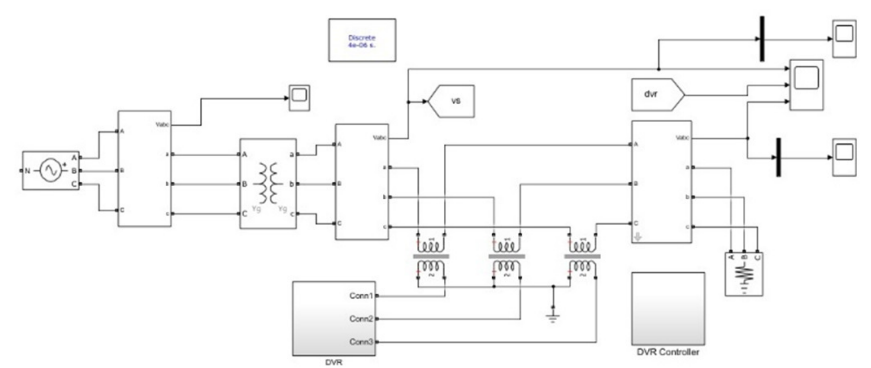

Fig. 6. Simulink model of the overall power system

The Total Harmonic Distortion (THD) at the supply voltage and the load voltage are measured by the Fast Fourier Transform (FFT) analysis tool of the Simulink model at different conditions of single phase, two phase, three phase sag and swell conditions. Each condition's THD results are shown and examined under each case.

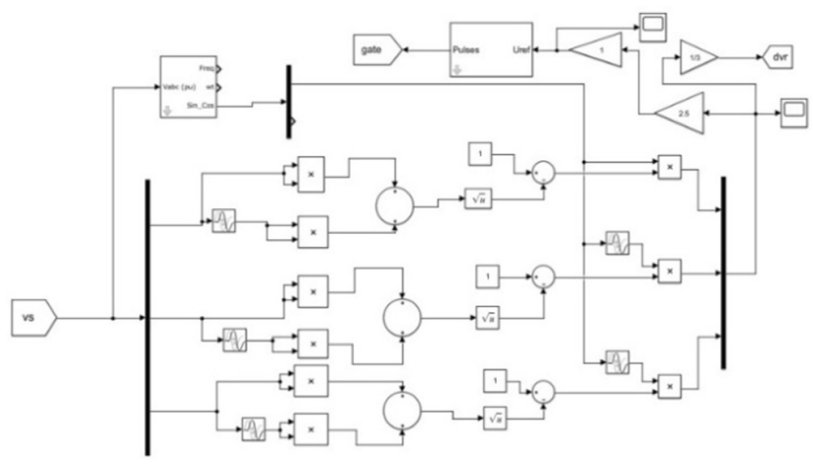

Fig. 7. Simulink model DVR control strategy with the novel control theory

\section{A. Case 1: Sag in One Phase}

\section{1) DVR Controlled with SRF Theory}

Figure 8 illustrates the supply voltage, the voltage injected by DVR, and the voltage across the load sag in one phase of the source voltage.

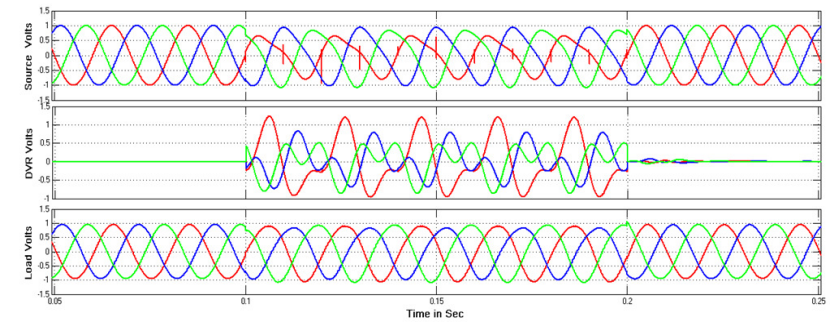

Fig. 8. Supply voltage, DVR voltage, and load voltage for a sag in one phase using SRF

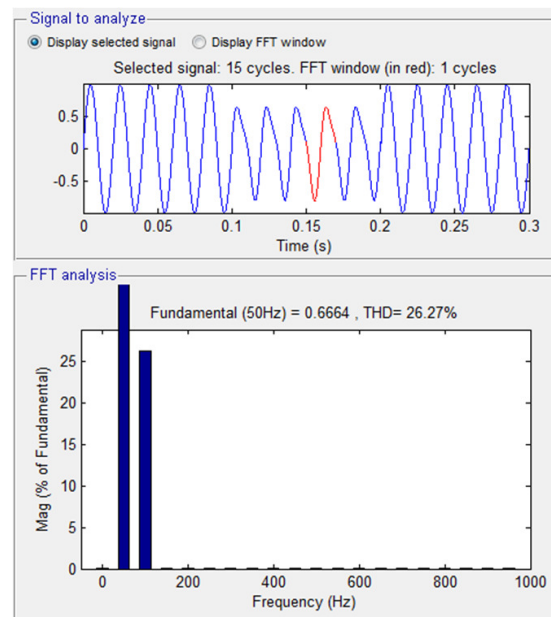

Fig. 9. THD in source voltage for sag in one phase using SRF

Compensating signals are injected by DVR and the magnitude of the voltage across the load remains constant. The harmonic distortion in the supply voltage and in the load voltage for a single phase sag using SRF is shown in Figures 9 
and 10 respectively. The source voltage is distorted by $26.27 \%$ and the load voltage by $4.52 \%$.

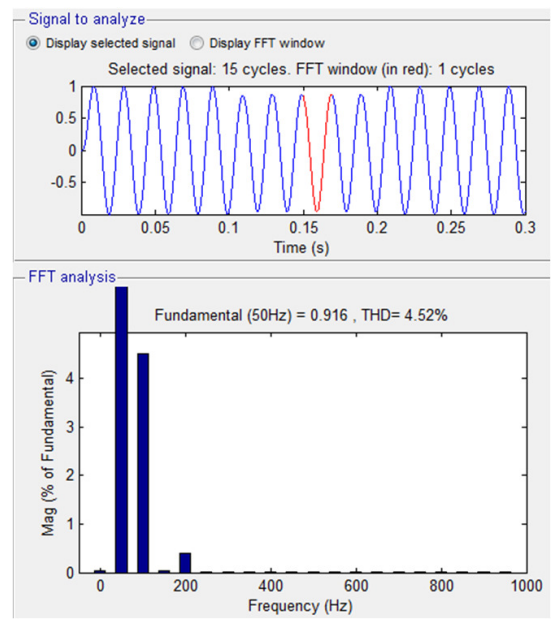

Fig. 10. THD in load voltage for a sag in one phase using SRF

\section{2) DVR Controlled with Novel Control Theory}

Figure 11 illustrates the supply voltage, the voltage injected by DVR, and the voltage across the load. One phase of the source voltage contains sag and compensating signals are injected by DVR and thus the voltage magnitude across the load remains constant.

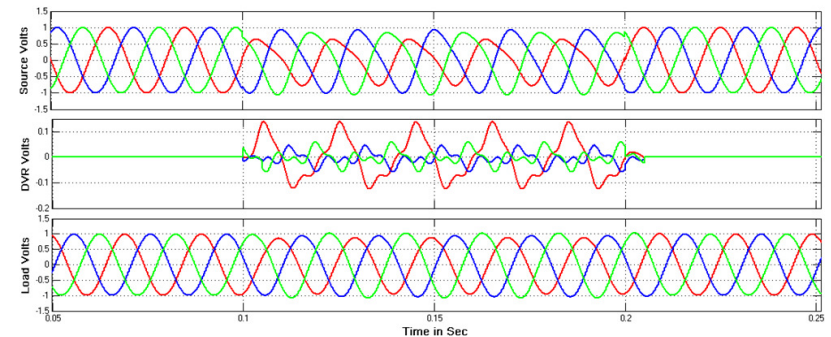

Fig. 11. Supply voltage, DVR voltage, and load voltage for a sag in one phase using the novel control theory

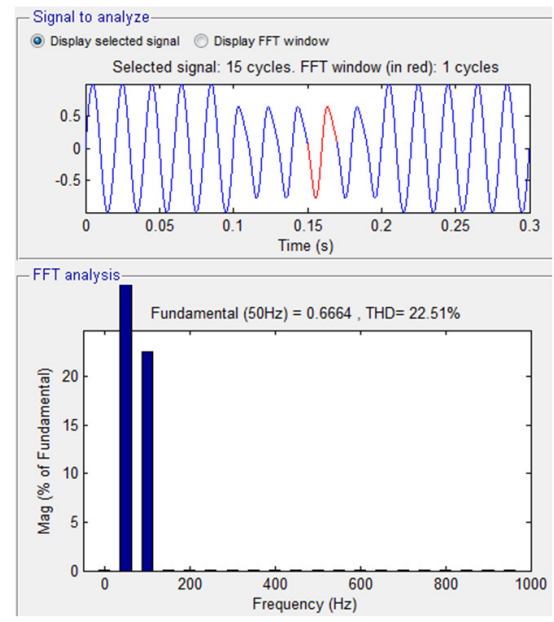

Fig. 12. THD in supply voltage for sag in one phase using the novel control theory

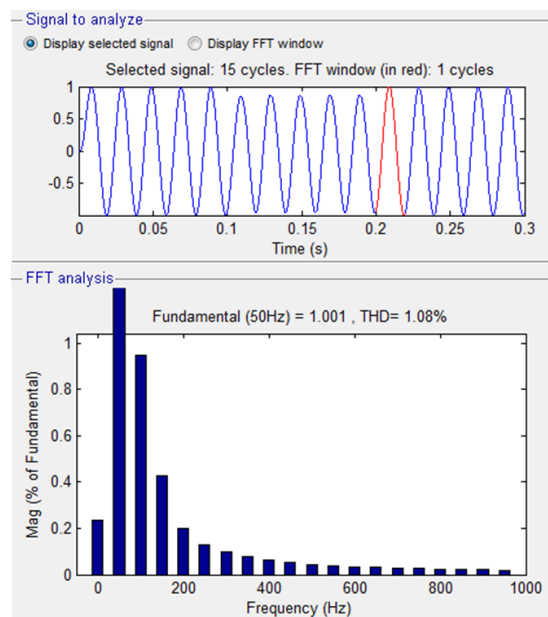

Fig. 13. THD in load voltage for sag in one phase using the novel control theory

The harmonic distortion in supply and load voltage is shown in Figures 12 and 13 respectively. The source voltage is distorted by $22.51 \%$ and the load voltage by $1.08 \%$.

\section{B. Case 2: Swell in One Phase}

\section{1) DVR Controlled with SRF Theory}

Figure 14 illustrates the supply voltage, the voltage injected by DVR, and the voltage across load with a system consisting of swell in one phase of the source voltage crossing the limit pu value.

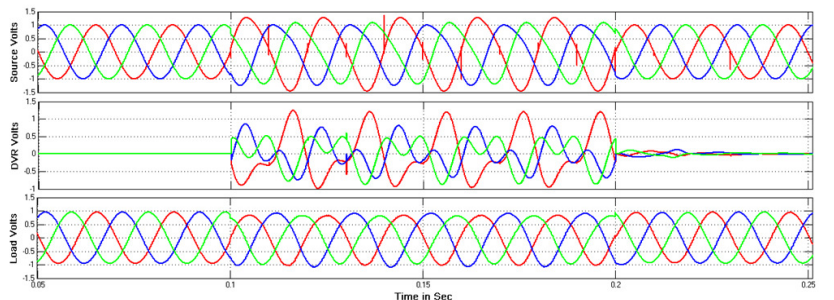

Fig. 14. Supply voltage, DVR voltage, and load voltage for swell in one phase using SRF

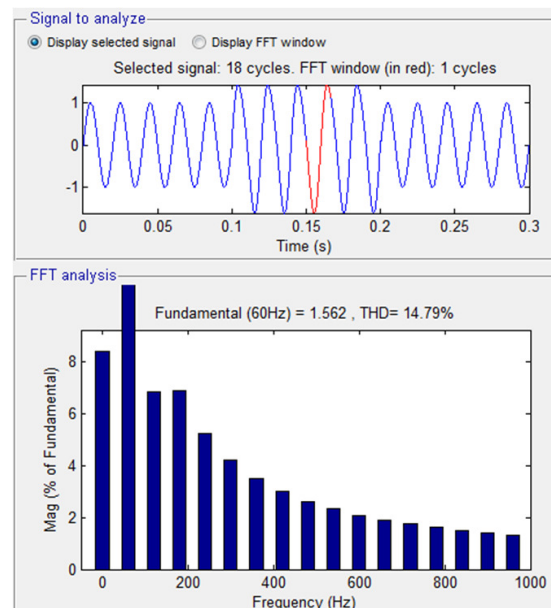

Fig. 15. THD in supply voltage for swell in one phase using SRF 


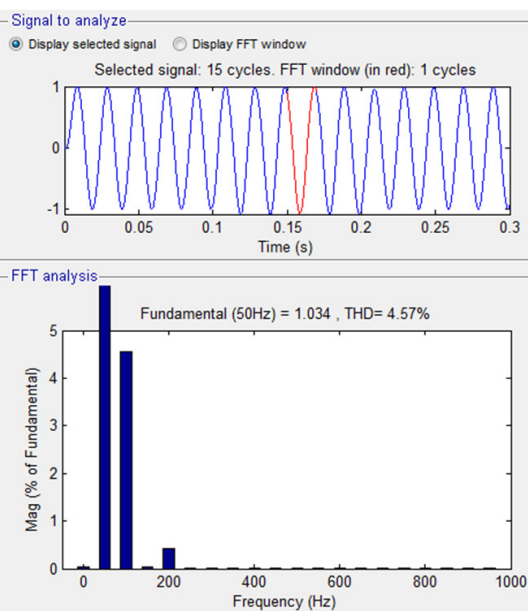

Fig. 16. THD in load voltage for swell in one phase using SRF

Compensating signals are injected by DVR and thus the voltage magnitude across the load remains constant. The harmonic distortion in the source and in the load voltage is shown in Figures 15 and 16 respectively. The source voltage is distorted by $14.79 \%$ and load voltage by $4.57 \%$.

\section{2) DVR Controlled with Novel Control Theory}

Figure 17 illustrates the supply voltage, the voltage injected by DVR, and the voltage across load with a swell in one phase of the supply voltage.

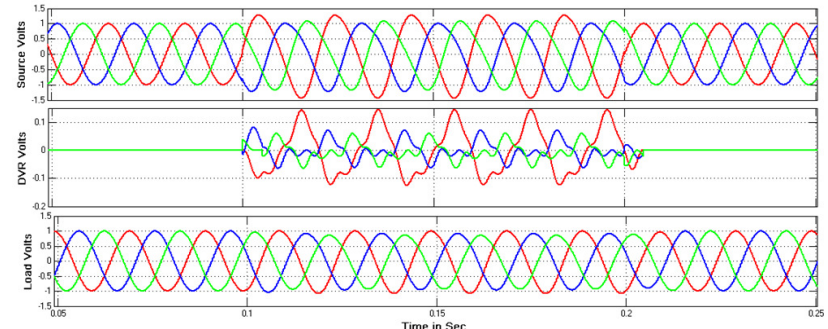

Fig. 17. Supply voltage, DVR voltage, and load voltage for swell in one phase using novel control theory

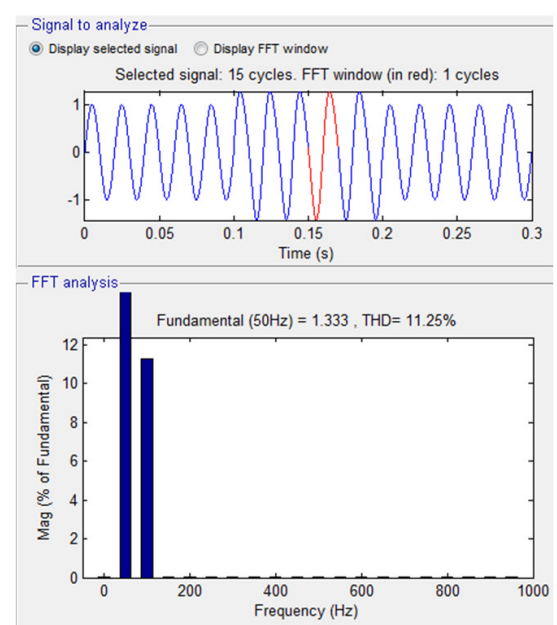

Fig. 18. THD in supply voltage for swell in one phase using the novel control theory
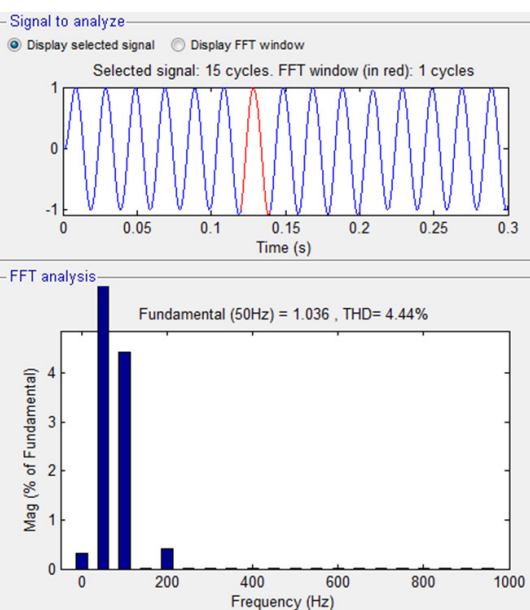

Fig. 19. THD in load votlage for swell in one phase using the novel control theory

Compensating signals are injected by DVR and the voltage magnitude across the load remains constant. The harmonic distortion in supply voltage and in load voltage is presented in Figures 18 and 19 respectively. The supply voltage is distorted by $11.25 \%$ and the load voltage $4.44 \%$.

C. Case 3: Sag in Two Phases

1) DVR Controlled with SRF Theory

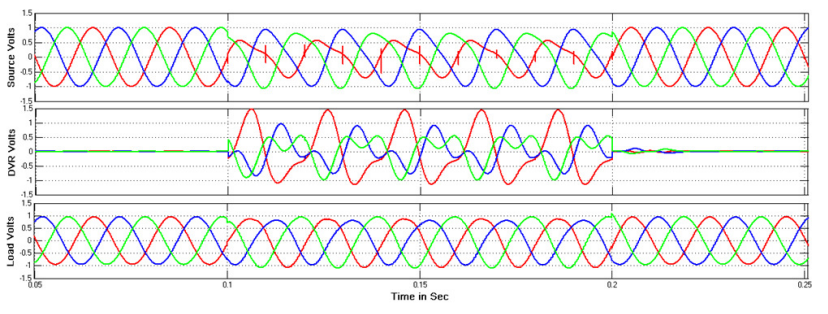

Fig. 20. Supply voltage, DVR voltage, and load voltage for sag in two phases using SRF

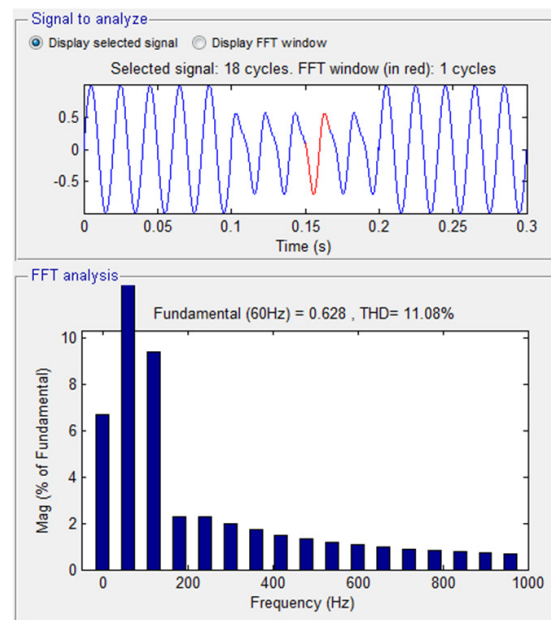

Fig. 21. THD in supply votlage for sag in two phases using SRF

Figure 20 illustrates the supply voltage, the voltage injected by DVR, and the voltage across the load with sags in two 
phases of the supply voltage. Compensating signals are injected by DVR, thus the voltage across the load remains constant. The harmonic distortion in supply load voltage is shown in Figures 21 and 22 respectively. The supply voltage is distorted by $11.08 \%$ and load voltage by $4.53 \%$.

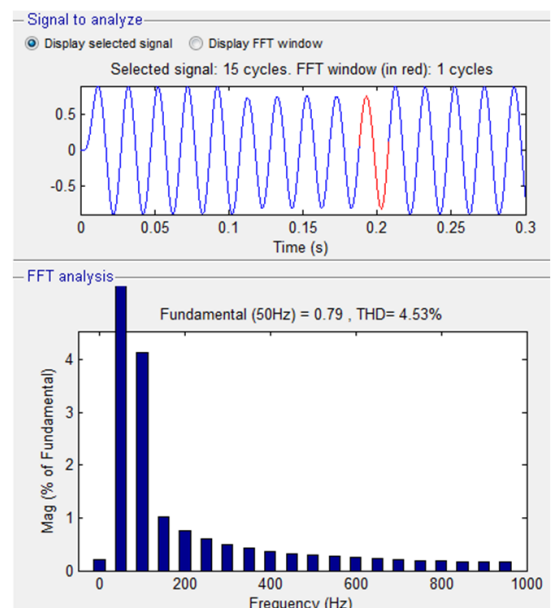

Fig. 22. THD in load votlage for sag in two phases using SRF

\section{2) DVR Controlled with Novel Control Theory}

Figure 23 illustrates the supply voltage, the voltage injected by DVR, and the voltage across the load.

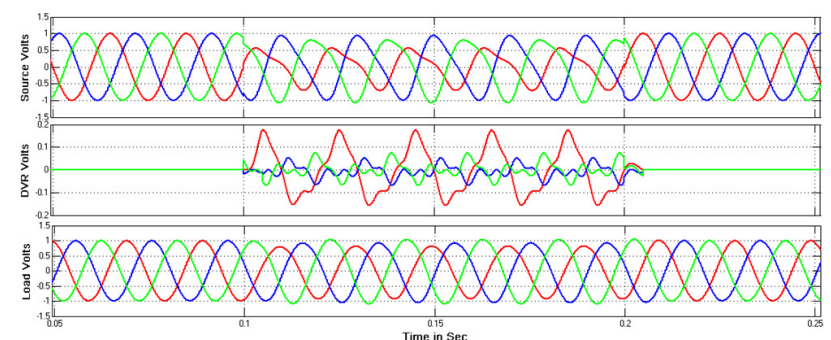

Fig. 23. Supply voltage, DVR voltage and load voltage for sag in two phases using novel control theory

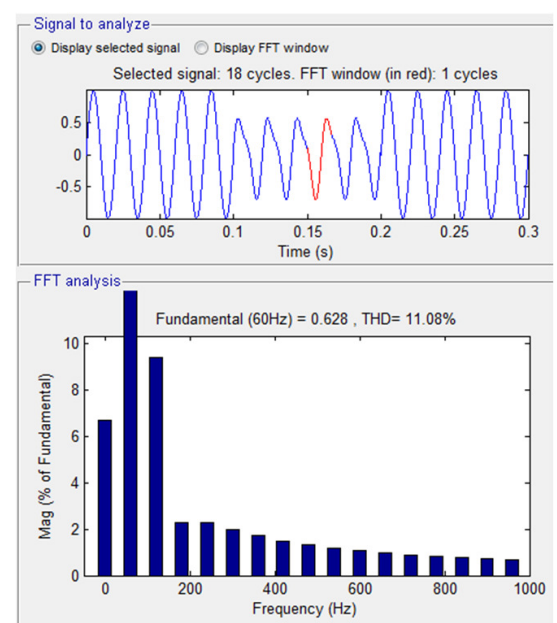

Fig. 24. THD in supply voltage for sag in two phases using novel control theory

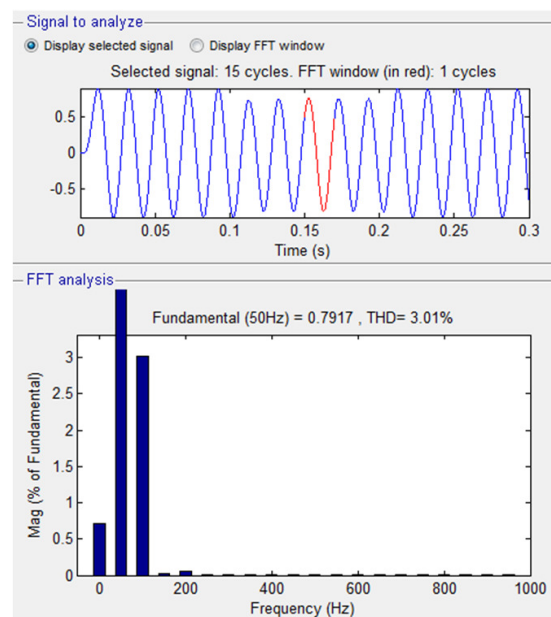

Fig. 25. THD in load voltage for sag in two phases using novel control theory

Two phases of the supply voltage contain sag and compensating signals are injected by DVR, thus the voltage across the load remains constant. The harmonic distortion in source and the load voltage is shown in Figures 24 and 25 respectively. The source voltage is distorted by $11.08 \%$ and load voltage is distorted by $3.01 \%$.

D. Case 4: Swell in Two Phases

1) DVR Controlled with SRF Theory

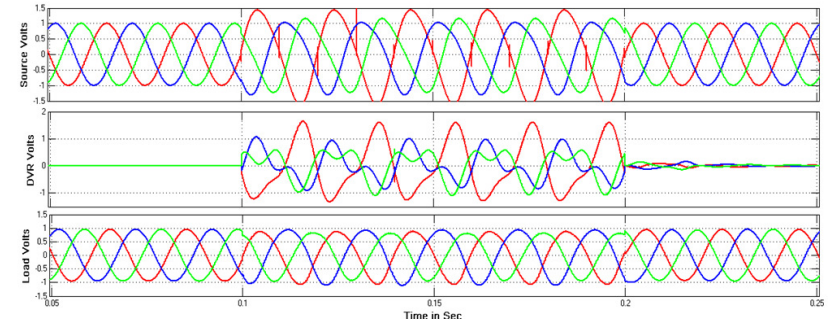

Fig. 26. Supply voltage, DVR voltage, and load voltage for swell in two phases using SRF

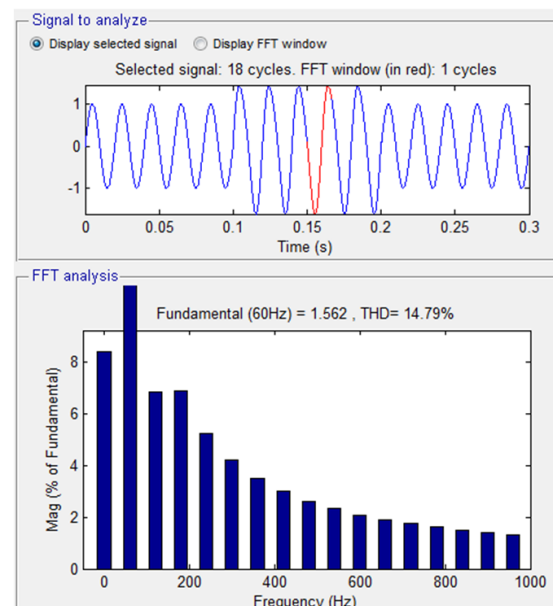

Fig. 27. THD in supply voltage for swell in two phases using SRF 


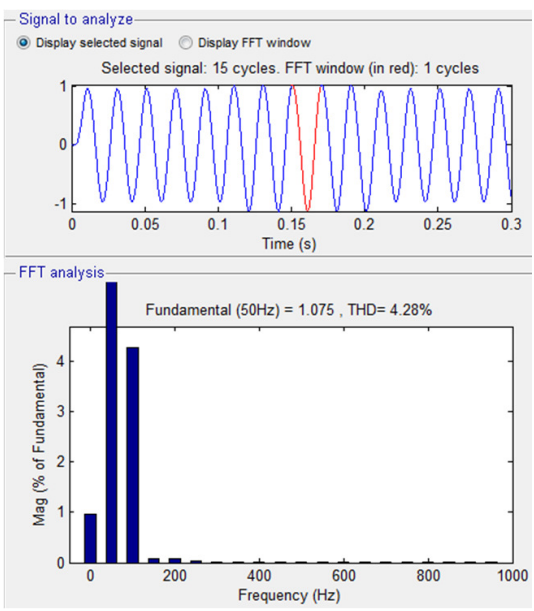

Fig. 28. THD in load votlage for swell in two phases using SRF

Figure 26 presents the supply voltage, the voltage injected by DVR, and the voltage across the load. Two phases of the supply voltage contain swell and the voltage magnitude across the load remains constant by compensating signals from the DVR. Harmonic distortion in supply and load voltage is shown in Figures 27 and 28 respectively. The source voltage is distorted by $14.79 \%$ and the load voltage by $4.28 \%$.

\section{2) DVR Controlled with Novel Control Theory}

Figure 29 illustrates the supply voltage, the voltage injected by DVR, and the load voltage.

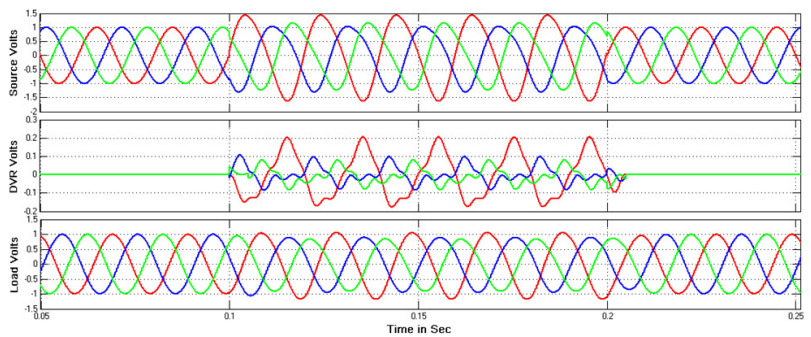

Fig. 29. Supply voltage, DVR voltage, and load voltage for swell in two phases using the proposed novel control theory

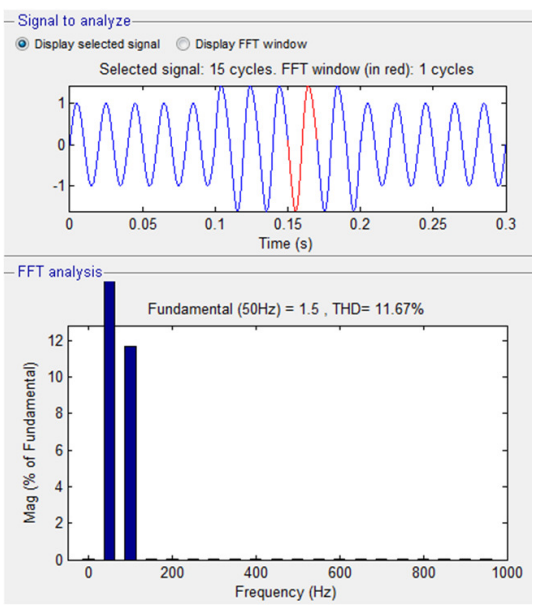

Fig. 30. THD in supply voltage for swell in two phases using the novel control theory
Compensating signals are injected by DVR and thus the voltage magnitude across the load remains constant. The harmonic distortion in the source voltage and the load voltage is shown in Figure 30 and 31 respectively. The source voltage is distorted by $11.67 \%$ and the load voltage by $3.09 \%$.

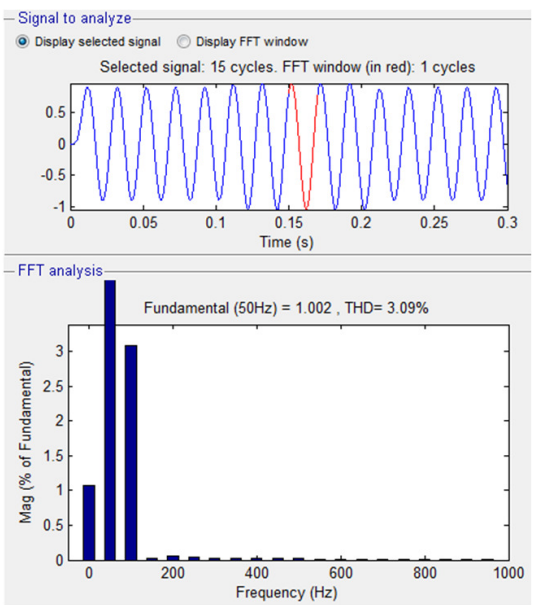

Fig. 31. THD in load voltage for swell in two phases using the novel control theory

E. Case 5: Sag in Three Phases

1) DVR Controlled with SRF Theory

Figure 32 illustrates the supply voltage, the voltage injected by DVR, and the voltage across the load.

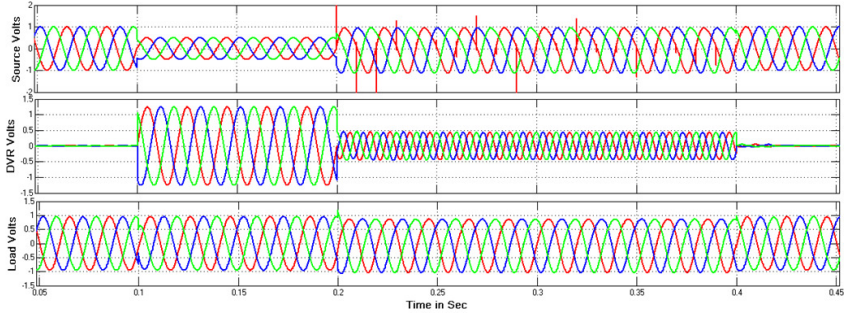

Fig. 32. Supply, DVR, and load voltage for sag in three phases sing SRF

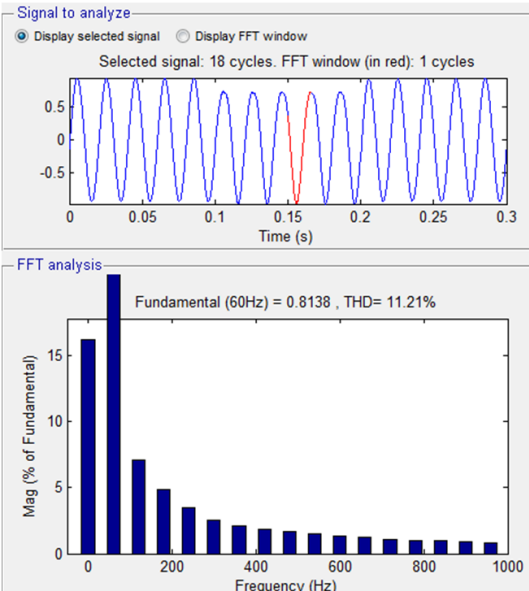

Fig. 33. THD in supply voltage for sag in three phases using SRF 


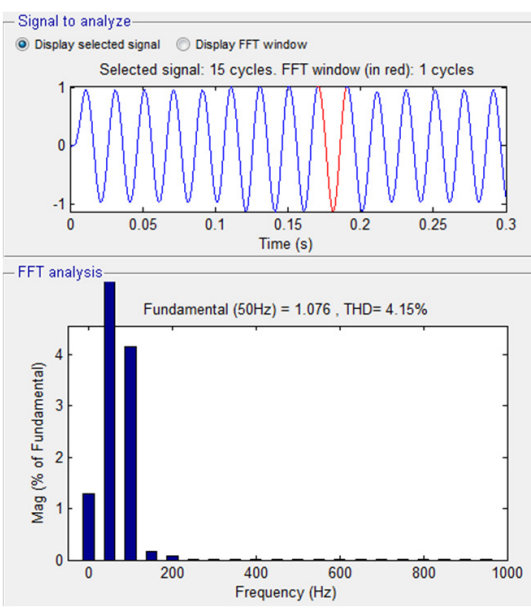

Fig. 34. THD in load voltage for sag in three phases using SRF

Three phases of the supply voltage contain sag and compensating signals are injected by DVR and the voltage across the load remains constant. The harmonic distortion in source and load voltage is shown in Figure 33 and 34 respectively. The source voltage is distorted by $11.21 \%$ and the load voltage by $4.15 \%$.

\section{2) DVR Controlled with Novel Control Theory}

Figure 35 illustrates the supply voltage, the voltage injected by DVR, and the voltage across the load.

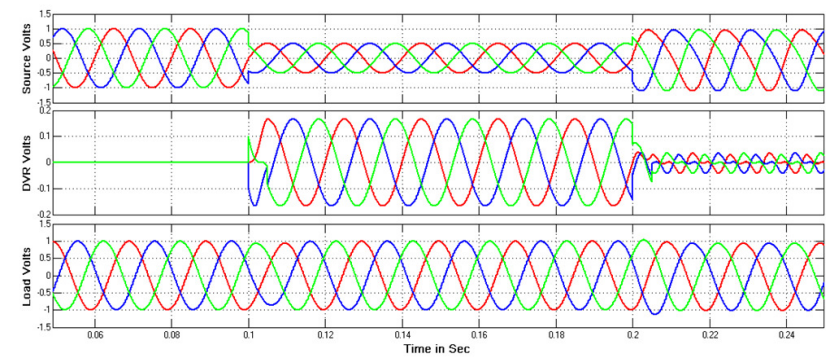

Fig. 35. Supply voltage, DVR voltage, and load voltage for sag in three phases using novel control theory

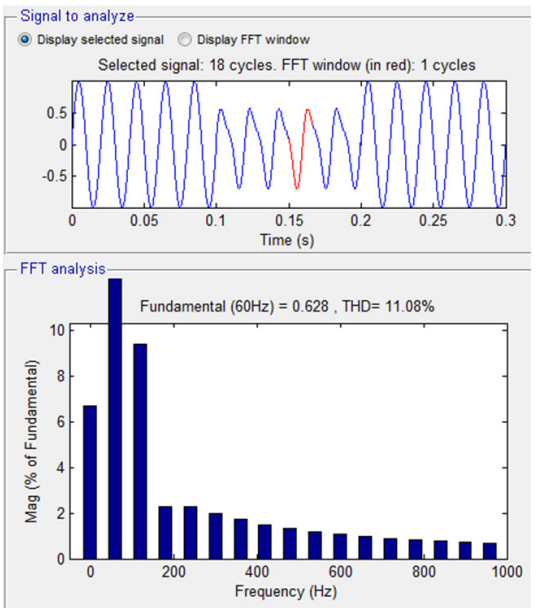

Fig. 36. THD in supply votlage for sag in three phases using the proposed control theory
Compensating signals are injected by DVR and the voltage across the load remains constant. The harmonic distortion in source and load voltage is shown in Figure 36 and 37 respectively. The supply voltage is distorted by $11.08 \%$ and load voltage is distorted by $2.20 \%$.

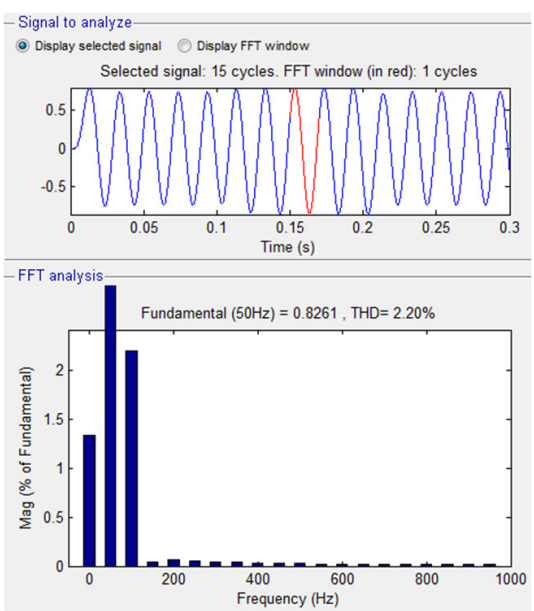

Fig. 37. THD in load voltage for sag in three phases using the proposed control theory

\section{F. Case 6: Swell in Three Phases}

\section{1) DVR Controlled with SRF Theory}

Figure 38 illustrates the supply voltage, the voltage injected by DVR, and the voltage across the load.

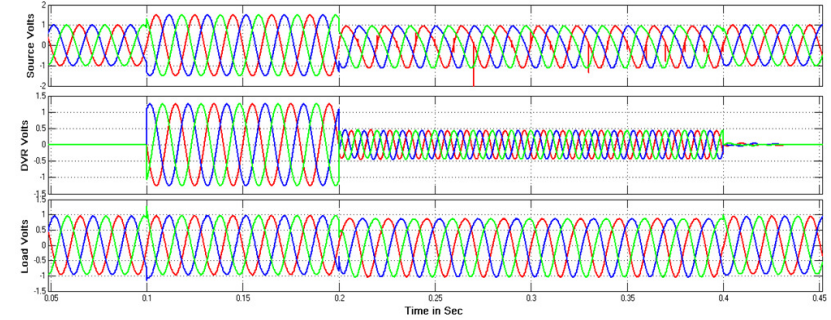

Fig. 38. Supply voltage, DVR voltage, and load voltage for swell in three phases using SRF

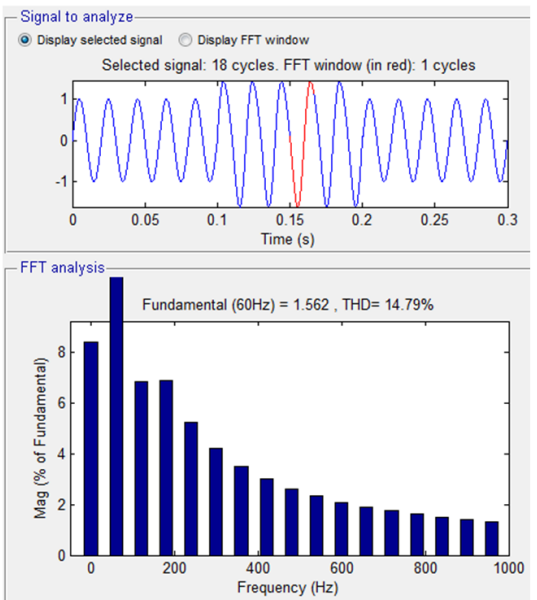

Fig. 39. THD in supply voltage for swell in three phases using SRF 


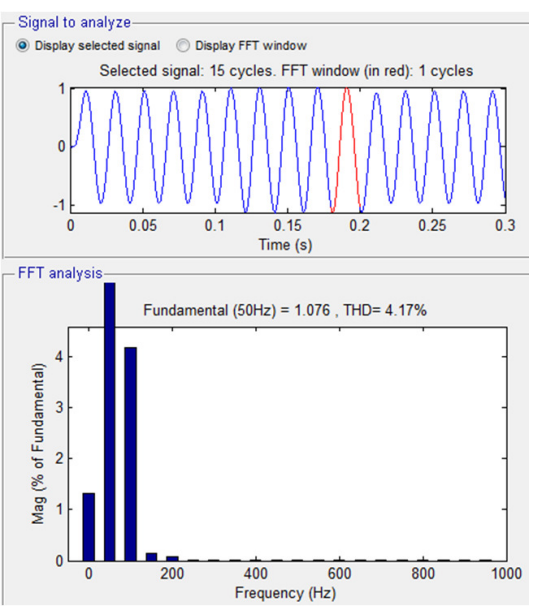

Fig. 40. THD in load voltage for swell in three phases using SRF

Compensating signals are injected by DVR and thus the voltage across the load remains constant. Harmonic distortion in supply and load voltage is shown in Figure 39 and 40 respectively. Supply voltage is distorted by $14.79 \%$ and load voltage is distorted by $4.17 \%$ for swell three phases using SRF

2) DVR Controlled with the Proposed Novel Control Theory

Figure 41 illustrates the supply voltage, the compensating voltage injected by DVR, and the voltage across the load.

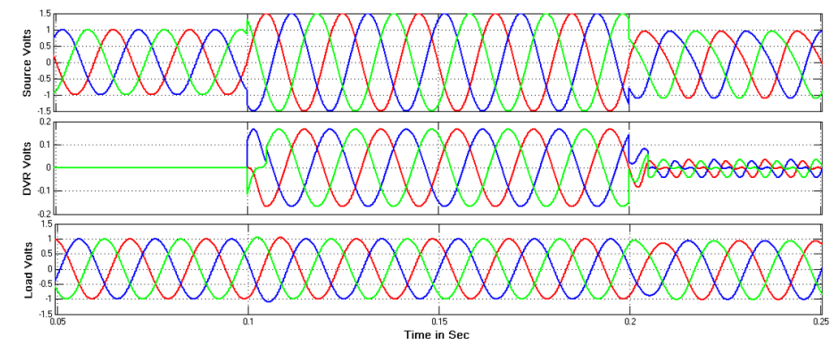

Fig. 41. Supply voltage, DVR injected voltage, and load voltage for swell in three phases using the proposed novel control theory

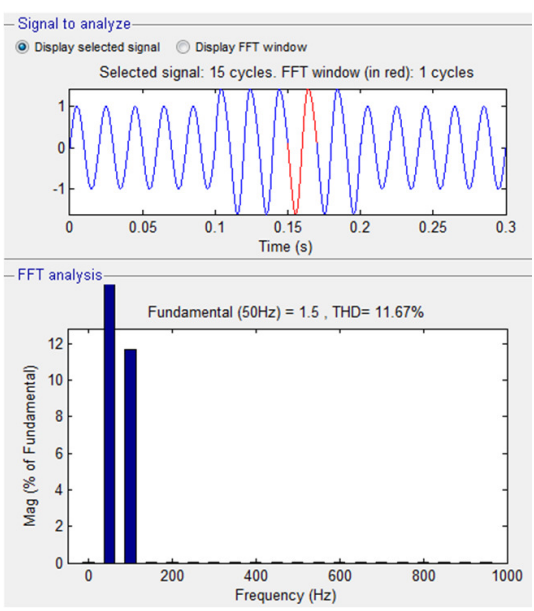

Fig. 42. THD in supply voltage for swell in three phases using the proposed novel control theory
Compensating signals are injected by DVR and the voltage magnitude across the load is kept constant. The harmonic distortion in supply and voltage is shown in Figure 42 and 43 respectively. The source voltage is distorted by $11.67 \%$ and the load voltage by $2.03 \%$.

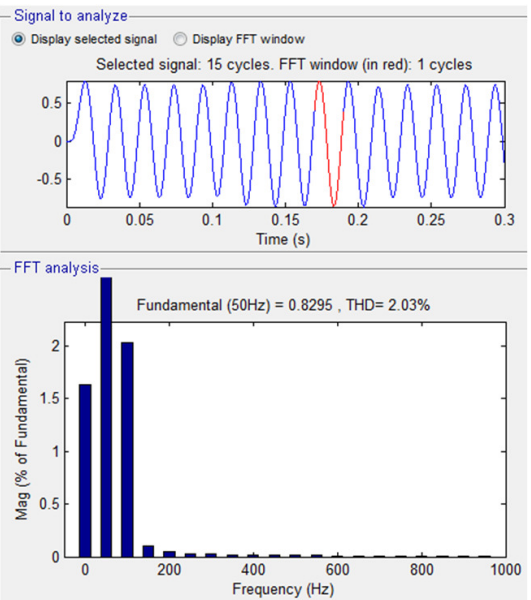

Fig. 43. THD in load voltage for swell in three phases using the novel control theory

\section{G. Result Comparison}

The comparison between the THD in source and load voltages for all cases is tabulated in Table II.

TABLE II. SOURCE AND LOAD VOLTAGE THD FOR SRF AND NOVEL CONTROL THEORY COMPARISON

\begin{tabular}{|c|c|c|c|c|c|}
\hline \multirow{2}{*}{ Case } & \multirow{2}{*}{ THD } & \multicolumn{2}{|c|}{ SRF Theory } & \multicolumn{2}{c|}{ Proposed } \\
\cline { 3 - 6 } & & $\begin{array}{c}\text { Source } \\
\text { Voltage }\end{array}$ & $\begin{array}{c}\text { Load } \\
\text { Voltage }\end{array}$ & $\begin{array}{c}\text { Source } \\
\text { Voltage }\end{array}$ & $\begin{array}{c}\text { Load } \\
\text { Voltage }\end{array}$ \\
\hline $\mathbf{1}$ & Sag in one phase & $26.27 \%$ & $4.52 \%$ & $22.51 \%$ & $1.08 \%$ \\
\hline $\mathbf{2}$ & Swell in one phase & $14.79 \%$ & $4.57 \%$ & $11.25 \%$ & $4.44 \%$ \\
\hline $\mathbf{3}$ & Sag in two phases & $11.08 \%$ & $4.53 \%$ & $11.08 \%$ & $3.01 \%$ \\
\hline $\mathbf{4}$ & Swell in two phases & $14.79 \%$ & $4.28 \%$ & $11.67 \%$ & $3.09 \%$ \\
\hline $\mathbf{5}$ & Sag in three phases & $11.21 \%$ & $4.15 \%$ & $11.08 \%$ & $2.20 \%$ \\
\hline $\mathbf{6}$ & Swell in three phases & $14.79 \%$ & $4.17 \%$ & $11.67 \%$ & $2.03 \%$ \\
\hline
\end{tabular}

It is clear that the THD in load voltage is less when the DVR is controlled with the proposed novel control method than when it is controlled with the SRF theory.

\section{CONCLUSION}

Dynamic Voltage Restorer is one of the forefront devices utilized for reducing voltage quality issues and for improving electrical power quality in a power system. The DVR stabilizes the load voltage irrespective of the condition in source voltage signal. This research work presents a DVR controlled with a novel control technique for compensating sag and swell types of voltage disturbances in a power system ensuring that the load receives stabilized voltage. The DVR is controlled using a novel unit vector control methodology and the results are compared with SRF theory-controlled DVR. The results indicate that the harmonic distortion in load voltage is less when the DVR is controlled with the novel control method compared to SRF theory-controlled DVR. 


\section{REFERENCES}

[1] C. Kumar, M. K. Mishra, "Predictive voltage control of transformer-less dynamic voltage restorer", IEEE Transactions on Industrial Electronics, Vol. 62, No. 5, pp. 2693-2697, 2015

[2] D. K. Tanti, M. K. Verma, B. Singh, O. N. Mehrotra, "Optimal placement of custom power devices in power system network to mitigate voltage sag under faults", International Journal of Power Electronics and Drive Systems, Vol. 2 No. 3, pp. 267-276, 2012

[3] G. Ramya, V. Ganapathy, P. Suresh, "Power quality improvement using multi-level inverter based DVR and DSTATCOM using neuro-fuzzy controller", International Journal of Power Electronics and Drive Systems, Vol. 8, No 1, pp. 316-324, 2017

[4] J. Chakravorty, G. Sharma, "DVR with modified Y source inverter and MCFC", Engineering, Technology \& Applied Science Research, Vol. 9, No. 1, pp. 3803-3806, 2019

[5] B. Ferdi, S. Dib, B. Berbaoui, R. Dehini, "Design and simulation of dynamic voltage restorer based on fuzzy controller optimized by ANFIS", International Journal of Power Electronics and Drive Systems, Vol. 4, No. 2, pp. 212-222, 2014

[6] A. Benhail, V. Kumar, "Modeling and simulation of a single phase Transformer less Dynamic Voltage Restorer (TDVR) for domestic application", 2017 International Conference on Innovations in Electrical, Electronics, Instrumentation and Media Technology, Coimbatore, India, February 3-4, 2017

[7] S. S. Rao, P. S. R. Krishna, S. Babu, "Mitigation of voltage sag, swell and THD using Dynamic Voltage Restorer with photovoltaic system", 2017 International Conference on Algorithms, Methodology, Models and Applications in Emerging Technologies, Chennai, India, February 16-18, 2017

[8] R. Saxena, M. Kushwah, "Optimization of voltage sag/swell using dynamic voltage restorer (DVR)", 2016 International Conference on Electrical Electronics and Optimization Techniques, Chennai, India, March 3-5, 2016

[9] P. T. Ogunboyo, R. Tiako, I. E. Davidson, "Effectiveness of Dynamic Voltage Restorer for unbalance voltage mitigation and voltage profile improvement in secondary distribution system", Canadian Journal of Electrical and Computer Engineering, Vol. 41, No. 2, pp. 105-115, 2018

[10] M. Pradhan, M. K. Mishra, "Dual P-Q theory based energy-optimized dynamic voltage restorer for power quality improvement in a distribution System", IEEE Transactions on Industrial Electronics, Vol. 66, No. 4, pp. 2946-2955, 2019

[11] P. Li, L. Xie, J. Han, S. Pang, P. Li, "New decentralized control scheme for a dynamic voltage restorer based on the elliptical trajectory compensation", IEEE Transactions on Industrial Electronics, Vol. 64, No. 8, pp. 6484-6495, 2017

[12] S. Suraya, K. S. R. Anjaneyulu, "Voltage quality improvement using DVR based on synchronous reference frame theory", International Journal of Advanced Research in Electrical, Electronics and Instrumentation Engineering, Vol. 5, No. 6, pp. 4966-4974, 2016

[13] S. Suraya, K. S. R. Anjaneyulu, "SRF controlled DVR for compensation of balanced \& Unbalanced voltage disturbances", International Journal of Electrical Engineering \& Technology, Vol. 7, No. 3, pp. 73-92, 2016

[14] S. Suraya, P. Sujatha, "A novel simplified unit vector theory for improvement of voltage quality in distribution system", Science Direct Energy Procedia 00 (2016) 000-000, SP-CRTPNFE, Elsevier, 2016

[15] S. Suraya, P. Sujatha, P. Bharath Kumar, "A novel control strategy based dynamic voltage restorer for compensation of voltage harmonics in distribution system", Indonesian Journal of Electrical Engineering and Computer Science, Vol. 7, No. 7, pp. 338-347, 2017

[16] S. Suraya, P. Sujatha, P. Bharath Kumar, "A novel control strategy for compensation of voltage quality problem in AC drives", International Journal of Power Electronics \& Drive Systems, Vol. 9, No. 1, pp. 8-16, 2018

[17] S. Suraya, P. Sujatha, P. Bharath Kumar, "Distributed generation with high voltage gain DC-DC converter integrated DVR as uninterrupted power supply", ARPN Journal of Engineering and Applied Sciences, Vol. 13, No. 9, pp. 3257-3265, 2018
[18] M. H. J. Bollen, "Characterisation of voltage sags experienced by threephase adjustable-speed drives", IEEE Transactions on Power Delivery, Vol. 12, No. 4, pp. 1666-1671, 1997

[19] R. Sedaghati, N. M. Afroozi, Y. Nemati, A. Rohani, A. R. Toorani, N. Javidtash, A. Heydarzadegan, H. Sedaghati, "A survey of voltage sags and voltage swells phenomena in power quality problems", International Journal of Scientific Research and Management, Vol. 1, No. 9, pp. 458462,2013 